\title{
PATIENT SAFETY: ANALYSIS OF THE IMPACT OF IMPLEMENTATION OF AUTOMATED DISPENSING CABINETS ON DRUG RETURN IN AN UNIVERSITY HOSPITAL
}

\author{
Ana Paula Deliberal ${ }^{1,2}$, Daniela Vescia Menna Barreto ${ }^{3}$, \\ Camila Pereira Menezes², Denise Bueno ${ }^{1,3,4,5}$
}

\begin{abstract}
Introduction: Patient safety and medication errors have received great attention and interest from health institutions. Drug return is a reverse logistics process that requires further analysis, because the delay or failure to return medications can create an accumulation of drugs in nursing units, favoring deviations and medication errors. The automated dispensing cabinets are a technological innovation that aims to reduce drug-related errors. The present study made an analysis of the amount of returned medications before and after the implantation of automated dispensing cabinets in a university hospital
\end{abstract}

Methods: This descriptive study presents a retrospective analysis of data on drug return collected from hospital reports published from 2013 to 2016.

Results: Before the implantation of automated dispensing cabinets, the mean percentage of returned medications was $27 \%$. In the first year after the implantation of automated dispensing cabinets, the mean percentage of returned medications was reduced to $4 \%$.

Conclusion: The implementation of the automated dispensing cabinets led to a reduction in drug return and in its associated risks, generating a positive impact on patient safety.

Keywords: Pharmacy service; hospital, automation; patient safety

Since the publication of the report entitled "To Err Is Human: Building A Safer Health System" by the Institute of Medicine (IOM) in 1999, patient safety and medication errors have received great attention and interest from health institutions ${ }^{1,2}$. In 2006, the IOM estimated that 400,000 drug-related adverse events occur in the United States yearly, with annual costs estimated at 3.5 billion dollars ${ }^{3,4}$. A study published in the British Medical Journal found that medical errors are the third leading cause of death in the United States ${ }^{5}$.

The hospital pharmacy plays a vital role in patient care by optimizing the management of the processes of drug standardization, acquisition, distribution, and dispensing, and has the main objective of promoting the accurate and timely dispensing of prescribed medications ${ }^{6}$. The use of technologies in the hospital pharmacy is a reality in several hospital institutions, being one of the methods that allow for high safety levels in the health care setting ${ }^{3}$. Technologies such as computerized medical prescription, clinical decision support, automated dispensing cabinets, bar code to distribute and administer medications (bedside checking) have become increasingly more prevalent in large hospitals ${ }^{2}$.

Among these technologies, it is worth highlighting automated dispensing cabinets, which are automated cabinets used to store and dispense drugs at the health care facilities attended by the patient, making it possible to control and monitor drug dispensing. Studies have shown that the use of automated
Clin Biomed Res. 2018;38(1):35-41

1 Pós-Graduação em Assistência Farmacêutica, Universidade Federal do Rio Grande do Sul (UFRGS). Porto Alegre, RS, Brasil.

2 Serviço de Farmácia, Seção de Gerenciamento e Logística de Medicamentos, Hospital de Clínicas de Porto Alegre. Porto Alegre, RS, Brasil.

3 Faculdade de Farmácia, Universidade Federal do Rio Grande do Sul (UFRGS). Porto Alegre, RS, Brasil.

4 Departamento de Produção e Controle de Medicamentos, Universidade Federal do Rio Grande do Sul (UFRGS). Porto Alegre, RS, Brasil.

5 Pós-Graduação Ensino em Saúde, Faculdade de Medicina, Universidade Federal do Rio Grande do Sul (UFRGS). Porto Alegre, RS, Brasil.

Corresponding author:

Denise Bueno

denise.bueno@ufrgs.br

Departamento de Produção e Controle de Medicamentos, Universidade Federal do Rio Grande do Sul (UFRGS)

Av. Ipiranga, 2752.

90610-000, Porto Alegre, RS, Brasil. 
dispensing cabinets is associated with time gain for the nursing staff, enabling longer patient care ${ }^{7}$.

These devices started to be used in hospitals in the United States in the 1980s, facilitating the transition to a decentralized drug distribution system. Literature reviews show that these automated systems have led to a decrease in the number of drug-related errors. A prospective observational before-and-after study conducted in Australia found a reduction of $64.7 \%$ in medication selection and preparation errors after the implementation of automated dispensing cabinets ${ }^{8}$. Currently, these cabinets are the main dispensing method of many institutions. This change in the pharmacy distribution model has encouraged the engagement of multidisciplinary teams and a constant update in theoretical background ${ }^{9}$. According to a systematic review ${ }^{10}$, the impact of automated dispensing cabinets on patient safety is highly specific and requires proper integration into a medication distribution process. This review concluded that automated dispensing cabinets have potential to decrease medication storage and recording errors and to decrease the time that nurses or pharmacists spent distributing psychotropic agents; however, results were not conclusive for other medications. There was no definitive evidence that using automated dispensing cabinets increased the time that nurses or pharmacists spent with patients. Based on these findings, it is recommended that, before deploying this technology, hospitals carefully examine their current systems and the benefits they hope to gain with the changes.

Additionally, potential risks for patient safety may be observed in some stages of the drug dispensing process, such as drug return, which is characterized as a reverse logistic process adopted by institutions to have an effective control of medication inventory and avoid wasting material and financial resources ${ }^{11}$. This process consists of checking the integrity of medications and materials returned from patient care units to the central pharmacy. The items meeting return requirements are reintegrated into the stock of this pharmacy to respond to the demand of other hospital wards ${ }^{12}$.

The main causes of drug return in hospitals are the non-use of medications prescribed as "only if needed" or "at the physician's discretion"; patient discharge, transfer to other unit, or death; and discontinuation of drug use ${ }^{11,13}$. Delay or failure in returning medications may generate an accumulation of medications in hospital wards, favoring deviations and medication errors ${ }^{11,14}$. From this perspective, the present study aimed to analyze the amount of drugs returned before and after the implementation of automated dispensing cabinets in Hospital de Clínicas de Porto Alegre (HCPA).

\section{METHODS}

\section{Study design}

This descriptive study presents a retrospective analysis of data on drug dispensing and return collected from management reports from 2013 to 2016 available in the Aplicativo de Gestão de Hospitais Universitários $\left(\mathrm{AGHUse}^{\circledR}\right)$ system and in the Sistema de Informações Gerencias (SIG ${ }^{\circledR}$.

This study was conducted at a large teaching hospital with an installed capacity of 843 beds and included inpatient units that implemented automated dispensing cabinets from 2014 to 2015. Data from 13 automated dispensing cabinets were assessed. These cabinets served eight inpatient units: three clinical inpatient units, two surgical inpatient units, one psychiatric inpatient unit, one intensive care unit, and one pediatric oncology unit. Data collected from reports were: total number of dispensed and returned medications during the period of analysis.

Moreover, the number of medications dispensed by and returned to the central pharmacy in 2016 was also collected, in order to perform an analysis of the amount of medications returned in units that are exclusively assisted by the central pharmacy. This study excluded inpatient units that were assisted by satellite pharmacies and that implemented automated dispensing cabinets in 2013 and in 2016. The coronary care unit was also excluded due to the lack of consistent data resulting from changes in classification and recording of data from this unit in the $\mathrm{AGHUse}{ }^{\circledR}$ system.

\section{Data analysis}

Data collected from management reports (total number of dispensed and returned medications) were tabulated using the Microsoft Excel software in order to calculate the percentage of dispensed and returned medications in the year before and in the 2 years after the implementation of automated dispensing cabinets and the percentage of medications dispensed by the central pharmacy. After calculating percentages for each unit, mean values were obtained.

\section{Ethical aspects}

This study was approved by the HCPA Graduate Studies and Research Group at Hospital de Clínicas de Porto Alegre (report number: 14-0716). All investigators signed a Data Use Agreement.

\section{RESULTS}

Prior to the implementation of automated dispensing cabinets, the central pharmacy dispensed the drugs to each patient for a period of 24 hours, according to medical prescription (Figure 1). Among inpatient 
units that did not implement automated dispensing cabinets, the mean percentage of returned medications was $37 \%$ in 2016 . Conversely, an average of $27 \%$ of medications dispensed in units with automated dispensing cabinets were returned to the central pharmacy in the year before the implementation of the cabinets (Figure 2).

The implementation of automated dispensing cabinets followed a schedule that was created according the administrative management of each unit, giving priority to critical units, units without satellite pharmacies, those located farther the central pharmacy, and those with the greatest amount of prescriptions. This study assessed 13 automated dispensing cabinets implemented in 8 inpatients units (Table 1). The medications made available in the automated dispensing cabinets were defined according to the consumption reports of each unit.

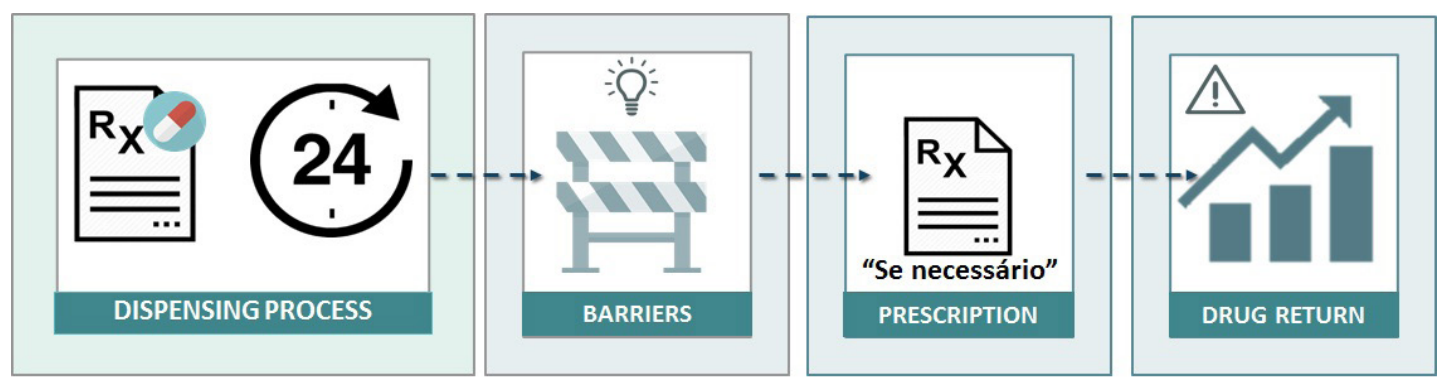

Figure 1: Drug dispensing flow prior to the implementation of automated dispensing cabinets.

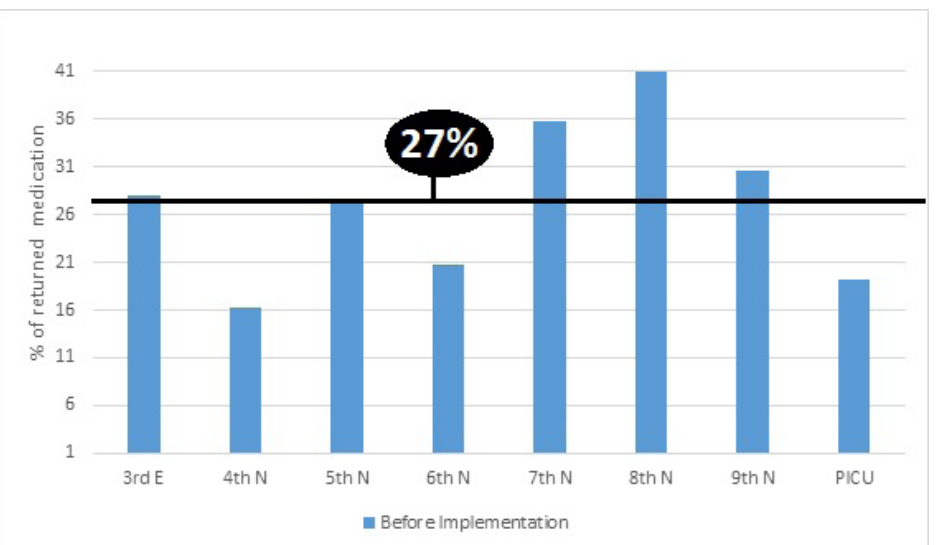

Figure 2: Percentage of returned medications in the year prior to the implementation of automated dispensing cabinets in the following wards: pediatric oncology unit (3rd E); psychiatric inpatient unit (4th N), clinical inpatient units (5th $\mathrm{N}$, 6th $\mathrm{N}$, and 7th $\mathrm{N}$ ), surgical inpatient units (8th $\mathrm{N}$ and 9th $\mathrm{N}$ ), and PICU. 3rd $\mathrm{E}=3$ rd floor east wing; 4th $\mathrm{N}=4$ th floor north wing; 5th $\mathrm{N}=5$ th floor north wing; 6 th $\mathrm{N}=6$ th floor north wing; 7th $\mathrm{N}=7$ th floor north wing; 8th $\mathrm{N}=8$ th floor north; 9th $\mathrm{N}=$ 9th floor north wing; $\mathrm{PICU}=$ pediatric intensive care unit.

Table 1: Location and number of implemented automated dispensing cabinets.

\begin{tabular}{ccccc}
\hline Hospital ward & $\begin{array}{c}\text { Bed } \\
\text { capacity }\end{array}$ & Specialty & Day of implementation & $\begin{array}{c}\text { Number of implemented } \\
\text { cabinets }\end{array}$ \\
\hline 4th N & 36 & Psychiatric unit & June 8th, 2014 & 1 \\
5th N & 45 & Clinical unit & December 8th, 2014 & 2 \\
6th N & 45 & Clinical unit & October 6th, 2014 & 2 \\
7th N & 45 & Clinical unit & November 24th, 2014 & 2 \\
8th N & 45 & Surgical unit & October 21st, 2014 & 2 \\
9th N & 45 & Surgical unit & April 27, 2015 & 2 \\
3rd E & 25 & Pediatric oncology unit & November 30th, 2015 & 1 \\
Pediatric & 13 & Pediatric intensive care unit & August 18th, 2014 & 1 \\
intensive care unit & & &
\end{tabular}


The flow of drug dispensing after the implementation of automated dispensing cabinets is shown in Figure 3. In this system, medications are made available for patient administration only at the time of administration and the staff does not have free access to the medication stock of the unit. According to hospital routine, before drug dispensing using an automated dispensing cabinet, medical prescriptions need to be assessed by the clinical pharmacists and the nursing staff needs to set up the automated scheduling of drug administration After that, the drugs become available for a period of two hours before and one hour after the time scheduled because of the interface between the hospital's prescribing system and the automated dispensing system. In order to access the automated dispensing cabinets can be accessed by previously registered users through biometric reading. All prescription drugs require bar code reading at the time of dispensing. In addition, psychotropic drugs and high-alert medications require blind count before withdrawal to enable stock control, i.e., the person withdrawing the medication should inform the number of medication units (e.g., ampoules or pills) available in the drawer without having access to the currently available amount. Blind count is used to improve stock control and dispensing safety.

This study found that automated dispensing cabinets dispensed an average of $82 \%$ of medications prescribed in inpatient units. As shown in Figure 4, PICU has the lowest mean percentage of medications dispensed by the automated dispensing cabinet $(56.82 \%)$ compared with the other units, whose means were above $80 \%$. After the implementation of automated dispensing cabinets, the mean percentage of medications returned to the central pharmacy was $4 \%$ in the first year and $4.5 \%$ in the second year (Figure 5).

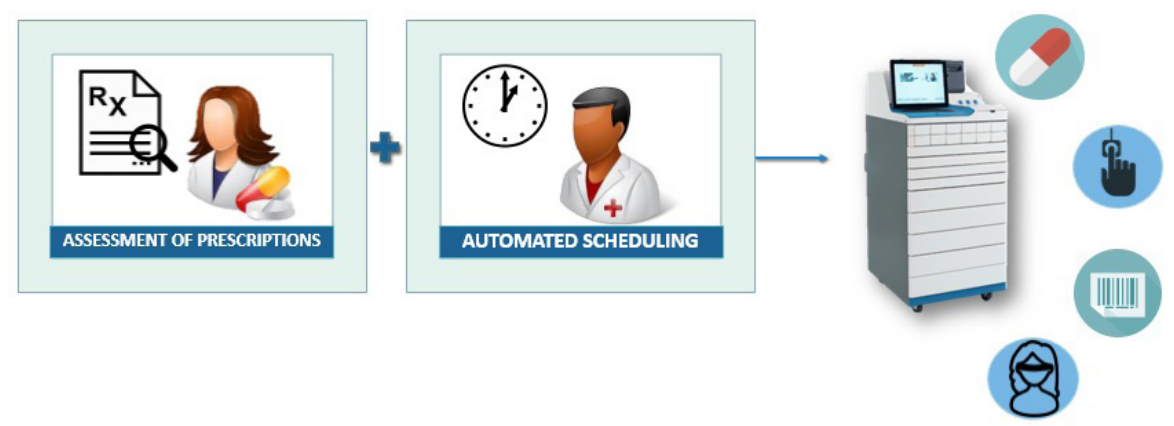

Figure 3: Drug dispensing flow after the implementation of automated dispensing cabinets.

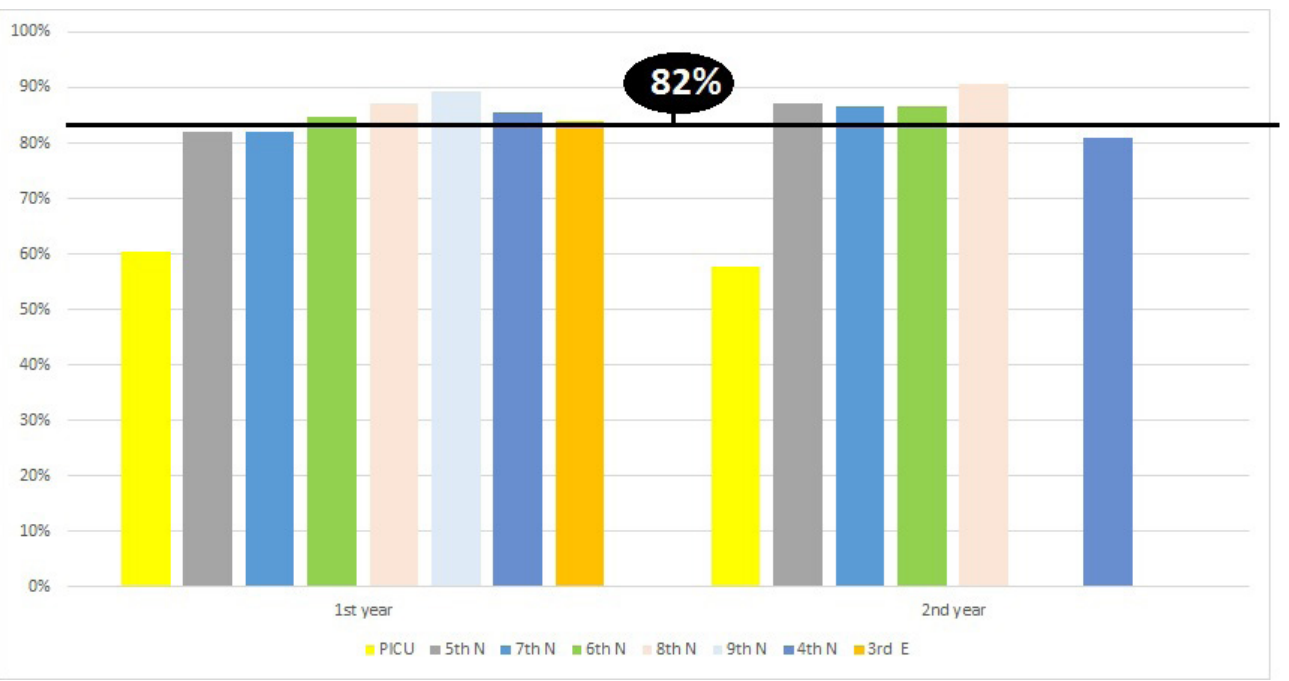

Figure 4: Percentage of medications dispensed by automated dispensing cabinets in the following wards: pediatric oncology unit (3rd E); psychiatric inpatient unit (4th N), clinical inpatient units (5th N, 6th N, and 7th N), surgical inpatient units (8th $\mathrm{N}$ and 9th $\mathrm{N}$ ), and PICU. 3rd $\mathrm{E}=$ 3rd floor east wing; 4th $\mathrm{N}=4$ th floor north wing; 5th $\mathrm{N}=5$ th floor north wing; 6th $\mathrm{N}=6$ th floor north wing; 7th $\mathrm{N}=7$ th floor north wing; 8th $\mathrm{N}=$ 8th floor north; 9th $\mathrm{N}=9$ th floor north wing; $\mathrm{PICU}=$ pediatric intensive care unit. 


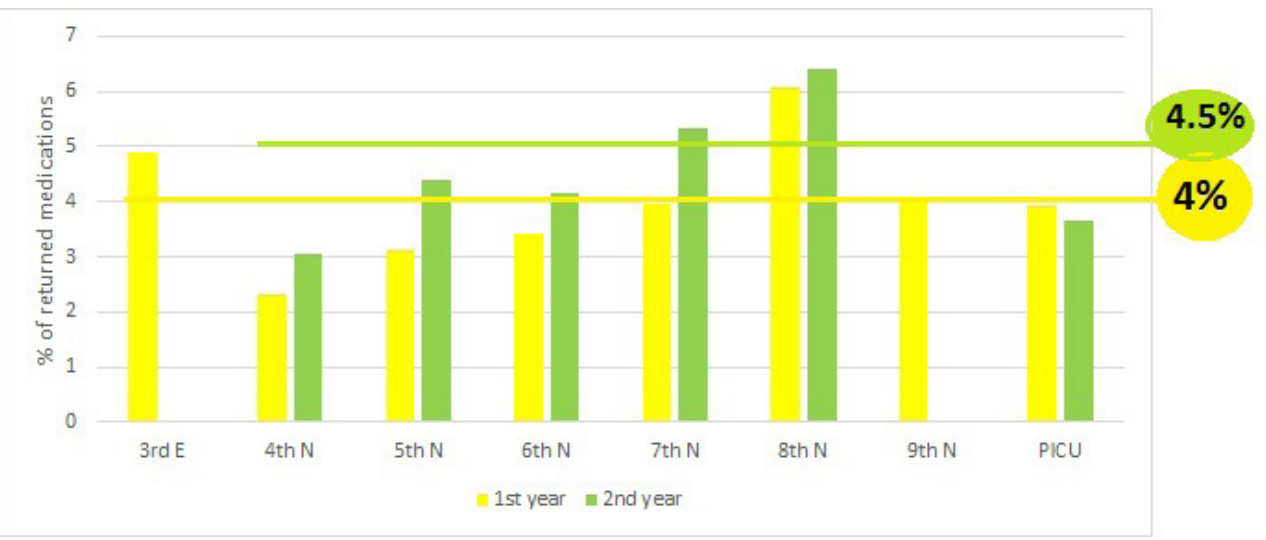

Figure 5: Percentage of medications returned in the first and second years after the implementation of automated dispensing cabinets in the following wards: pediatric oncology unit (3rd E); psychiatric inpatient unit (4th $\mathrm{N}$ ), clinical inpatient units (5th $\mathrm{N}, 6$ th $\mathrm{N}$, and 7th $\mathrm{N}$ ), surgical inpatient units (8th $\mathrm{N}$ and 9th $\mathrm{N}$ ), and PICU. 3rd $\mathrm{E}=3 \mathrm{rd}$ floor east wing; 4th $\mathrm{N}=4$ th floor north wing; 5 th $\mathrm{N}=5$ th floor north wing; 6th $\mathrm{N}=6$ th floor north wing; 7th $\mathrm{N}=7$ th floor north wing; 8th $\mathrm{N}=$ 8th floor north; 9th $\mathrm{N}=$ 9th floor north wing; $\mathrm{PICU}=$ pediatric intensive care unit.

\section{DISCUSSION}

This study evaluated data from 13 automated dispensing cabinets that were implemented from 2014 to 2015. The unit that implemented its first automated dispensing cabinet in 2013 was excluded from the convenience analysis because this cabinet was not implemented during the period established in the inclusion criteria. The units that implemented the cabinets in 2016 were also excluded from the sample because it was not possible to analyze the first and second years after implementation. The coronary care unit was excluded from the study because it experienced changes in the classification and recording of data in the AGHUse ${ }^{\circledR}$ system, which made it impossible to collect consistent data.

In the present study, a great number of returned medications (up to $41 \%$ ) was observed in the year prior to the implementation of automated dispensing cabinets, i.e., when medications were dispensed for a 24-hour period (individualized system) (Figure 2). When analyzing data for units that did not implement automated dispensing cabinets, the mean percentage of returned medications was $37 \%$ in 2016 .

After the implementation of automated dispensing cabinets, the mean percentage of returned medications reduced from $27 \%$ to $4 \%$ in the first year and to $4.5 \%$ in the second year. There was an increase of $0.5 \%$ in the mean percentage of returned medications in the second year of implementation of cabinets compared with the first one; however, this percentage may be considered low when compared with that of the pre-implementation period ( $27 \%$ ). This study could not establish the cause of the abovementioned increase. Post-implementation findings may be attributed to the decentralization of the drug dispensing process, the availability of medications for patient administration only at the time of administration, and the proper selection of the medications that should be made available in the automated dispensing cabinet. Our results corroborate the need to change the culture of prescribing and dispensing medications as "only if needed" or "at the physician's discretion". The implementation of automated dispensing cabinets had a positive impact on the percentage of medications returned from inpatient units.

In a before-and-after comparative study, Moreno et al. found that the consumption of medications, especially those used to treat mild diseases (acetaminophen, ibuprofen, etc.) was $56.49 \%$ lower after the implementation of automated dispensing cabinets, leading to a $15.7 \%$ reduction in costs ${ }^{15}$. A study conducted to observe the economic impact of replacing a centralized dispensing system with a decentralized one in an intensive care unit found a reduction of $24 \%$ in medication consumption ${ }^{16}$. A cost-benefit analysis revealed a reduction of up to $37 \%$ in medication stock after the implementation of automated dispensing cabinets and a favorable cost-benefit relationship (1.95) $)^{17}$. Despite their different scopes, the above studies indirectly reflect a possible relationship between the implementation of automated dispensing cabinets and a decrease in the amount of returned medications, since medication consumption was reduced after implementation.

Automated dispensing cabinets are used to provide about $82 \%$ of prescription drugs in the hospital (Figure 4), except for refrigerated drugs, drugs not selected by the hospital, and rarely prescribed drugs. 
Medications not available in automated dispensing cabinets (18\%) are dispensed in the central pharmacy (Figure 1). Systems combining centralized and decentralized methods and using automated and/or manual procedures are known as mixed dispensing systems ${ }^{3}$.

Among the inpatient units analyzed in this study, the PICU was the one the lowest percentage of medications dispensed by the automated dispensing cabinet $(56.82 \%)$, which may be explained by clinical specificities associated with the profile of admissions to this unit. According to a previous study ${ }^{18}$, the two leading causes of PICU admissions are post-operative care and respiratory tract problems. Because of that, there was a great number of prescriptions containing pancuronium and intravenous salbutamol. Neither of these two medications are available in automated dispensing cabinets, the first because it is thermolabile and the latter due to practical reasons, since it requires the prescription of a large amount of medication.

The major limitation of this study is the assessment of institutional reports that describe data from the research institution but may not reflect the reality of other hospital institutions. Another limitation is the lack of analysis of data from the first automated dispensing cabinet implemented in the hospital; thus, it is not possible to determine whether the results would follow the same trend observed in the inpatient units analyzed here.

Drug return is a reality in the hospital setting that should be monitored to avoid compromising patient safety. Results obtained before and after the implementation of automated dispensing cabinets in the research hospital showed that there was a decrease in the amount of returned medications after these cabinets were implemented in the units assessed in the present study. The planning and monitoring of new health technologies such as automated dispensing cabinets seem to contribute in reducing drug return and its associated risks, which generates a positive impact on rational drug use, patient safety, and time gain for health care professionals, enabling longer patient care.

\section{Acknowledgements}

We would like to thank the staff of the Pharmacy Service - Department of Drug Management and Logistics of Hospital de Clínicas de Porto Alegre, especially the pioneers who made every effort to develop and improve the efficiency of the current model of drug dispensing in Hospital de Clínicas de Porto Alegre: Simone Dalla Pozza Mahmud, Mayde Torriani, Graziela Cristine Goerck, Leonardo Feix, and Thalita Silva Jacoby. All these people will continue the research started in this study, thus supporting and encouraging the production of scientific papers in the area.

\section{Conflicts of interest}

The authors declare no conflicts of interest.

\section{REFERENCES}

1. National Patient Safety Foundation. Free from harm: accelerating patient safety improvement fifteen years after To Err Is Human. Boston (MA): National Patient Safety Foundation; 2015

2. Cochran GL, Barrett RS, Horn $\mathrm{SD}$. Comparison of medication safety systems in critical access hospitals: Combined analysis of two studies. Am J Health Syst Pharm. 2016;73(15):1167-73. http:// dx.doi.org/10.2146/ajhp150760. PMid:27440623.

3. Borges WM Fo, Ferracini FT. Prática farmacêutica no ambiente hospitalar. 2nd ed. Rio de Janeiro (RJ): Atheneu; 2010.

4. Cipriano SL. Proposta de um conjunto de indicadores para utilização na Farmácia Hospitalar com foco na
Acreditação Hospitalar [dissertação]. São Paulo (SP): Universidade de São Paulo; 2004.

5. Makary MA, Michael D. Medical error - the third leading cause of death in the US. BMJ. 2016; 353. https://doi. org/10.1136/bmj.i2139.

6. Romero A. Managing medicines in the hospital pharmacy: logistics inefficiencies. San Francisco (CA): In: Proceedings of the World Congress on Engineering and Computer Science; 2013 Oct 23-25; San Francisco. Hong Kong: IAENG. Vol. 2 [cited 2017 Sep 17]. Available from: http://www. iaeng.org/publication/WCECS2013/ WCECS2013_pp1120-1125.pdf

7. Menezes CP. Percepção da enfermagem e avaliação da segurança do paciente na implantação de dispensários eletrônicos [dissertação]. Porto Alegre (RS): Universidade Federal do Rio Grande do Sul; 2016.

8. Fanning L, Jones N, Manias E. Impact of automated dispensing cabinets on medication selection and preparation error rates in an emergency department: a prospective and direct observational before-and-after study. J Eval Clin Pract. 2016;22(2):156-63. http://dx.doi.org/10.1111/jep.12445. PMid:26346850.

9. Institute for Safe Medication Practices (ISMP). Guidance on the interdisciplinary safe use of automated dispensing cabinets. Horsham (PA): ISMP; 2008. [cited 2017 Sep 17]. Available from: https://www.ismp.org/ tools/guidelines/ADC_Guidelines_ Final.pdf. 
10. Tsao NW, Lo C, Babich M, Shah K, Bansback NJ. Decentralized automated dispensing devices: systematic review of clinical and economic impacts in hospitals. Can J Hosp Pharm. 2014;67(2):13848. http://dx.doi.org/10.4212/cjhp. v67i2.1343. PMid:24799724.

11. Limberger JB, Santos TS, Prediger $\mathrm{KC}$, Ferrony DA, Bertagnolli SMM. Análise do fluxo de distribuição e estorno de medicamentos em hospital filantrópico de Santa Maria, RS. Rev Adm Hosp. 2013;10:36-44.

12. De Souza AA, Lima LCM, Xavier AG, Cruz NG. Análise do sistema de controle interno de hospitais: estudo de casos múltiplos no setor farmácia. In: XXXI Encontro Nacional de Engenharia de Produção; Belo Horizonte (MG). Rio de Janeiro: ABEPRO; 2011. [cited 2017 Sep 17].
Available from: http://www.abepro. org.br/biblioteca/enegep2011_TN_ STO_137_869_18199.pdf

13. Souza JS, Marques BC, MoriguchiJeckel CM, Goerck G, Balen M. Avaliação dos Estornos de Medicamentos no Hospital São Lucas da PUCRS. In: IX Salão de Iniciação Científica PUCRS; 2008; Porto Alegre (RS). Porto Alegre (RS): PUCRS; 2008.

14. Cassiani SHB, Miasso AI, Silva AEBC, Fakin FT, Oliveira RC. Aspectos gerais e número de etapas do sistema de medicação de quatro hospitais brasileiros. Rev Lat Am Enfermagem. 2004;12(5):7819. http://dx.doi.org/10.1590/ S0104-11692004000500012. PMid:15717078.
15. Moreno M, Bohórquez M, Moreno V. Evaluation of the efficiency of an automated dispensing cabinet (ADC) in a ward of internal medicine. Rev OFIL. 2016;26:103-10.

16. Zafra Fernández JL, Isla Tejera B, Del Prado Llergo JR. An automatic dispensing system medications effect in pharmaceutical expenditure and satisfaction user level. Enferm Glob. 2012;11:250-61.

17. Poveda JLA., Garcia CG., Hernández, $\mathrm{SM}$, Valladolid WA. Análisis costebeneficio de la implantación de los sistemas automáticos de dispensación de medicamentos en la Unidades de Críticos y Urgencias. Farm Hosp. 2003:2003:14-21.

18. Becker GC, Machado FR, Bueno D. Perfil de utilização de medicamentos em pacientes pediátricos em cuidados intensivos. Rev Bras Farm Hosp Serv. 2016;7:42-7. 